\title{
MATEMÁTICA E COMPLEXIDADE
}

\section{Marcelo Reicher Soares}

Prof. Dr. do Departamento de Filosofia da Faculdade de Filosofia e Ciências - UNESP, Campus de Marília. Pós-Doutorado no Centro de Lógica, Epistemologia e História da Ciência CLE-UNICAMP. Email: reicher@fc.unesp.br

\section{RESUMO}

Neste trabalho discorre-se brevemente sobre a noção de sistemas complexos, é apresentada uma caracterização de tais sistemas a partir de algumas de suas propriedades inerentes comumente aceitas. A partir daí é traçado um paralelo entre essa abordagem dos sistemas complexos e o ceticismo metodológico de Descartes, descrito pelas regras de pensar corretamente que ele apresentou em seu Discours de la methode. Trataremos da abordagem matemática de complexidade de um sistema, que é feita, em geral, por meio do estudo de sistemas dinâmicos, nestes a modelagem dos fenômenos se dá basicamente utilizando-se os sistemas de equações diferenciais. Para ilustrar esse processo de modelagem fez-se uma apresentação, na qual se procurou ser o mais intuitivo possível, do conceito de atrator estranho que está fundamentalmente associado às equações de Lorenz.

PALAVRAS-CHAVE: Sistemas complexos. Sistemas dinâmicos. Atrator estranho. Equações de Lorenz.

\section{MATHEMATICS AND COMPLEXITY}

\begin{abstract}
In this work we briefly discuss about the notion of complex systems, trying to characterizethem from some commonly accepted inherente properties. We draw a parallel of this approach with skepticism of Descartes, described by the rules of thinking correctly that he presented in his Discours de la methode. We will treat with the matematical approach of complexity, that is generally taken, by mean of the study of dinamic systems which, in turn, use differential equation systems to model the phenomena. In order to illustrate this modeling process, we make a presentation, that we intend it will be intuitive, of the concept of strange attractor which is fundamentally associated with the Lorenz equations.
\end{abstract}


KEYWORDS: Complex systems. Dynamical systems. Strange attractor. Lorenz equations.

\section{INTRODUÇÃO}

Se pensarmos acerca do código genético, na maneira como os genes, constituintes do genótipo, condicionam o fenótipo, e em como a configuração genotípica sofre mudanças relativamente frequentes, a partir da interação do indivíduo portador desse genótipo com o meio, veremos a complexidade oriunda da tentativa de modelar tal processo. Em um estudo recente, publicado na revista "Nature" (PRÜFER, 2012), é apresentado o sequenciamento genético do macaco Bonobo, tal estudo revela a coincidência de 98,7\% entre o material genético deste com o humano, igual porcentagem de coincidência já havia sido encontrada entre humano e Chimpanzé. Tal fato evidencia como, em algumas áreas, grandes mudanças podem ser produzidas a partir de pequenas alterações, no caso, a partir de uma diferença de apenas 1,2\% no genótipo do ancestral a eles comum, tem um efeito impactante.

Outro fenômeno muito famoso que apresenta essa desproporção entre causa e efeito ocorreu na década de sessenta a partir do trabalho do meteorologista Edward Lorenz, no Instituto de tecnologia de Massachusetts. Lorenz, casualmente, observou que alterações muito pequenas na alimentação dos dados iniciais em seu modelo computacional para o estudo da evolução das condições climáticas, produziam, em período relativamente pequeno de tempo, mudanças de grande magnitude (LORENZ, 1963).

Cientificamente o fenômeno observado por Lorenz teve um grande impacto e muitas consequências, algumas até pitorescas como o surgimento da expressão "efeito borboleta", segundo a qual, o simples bater das asas de uma borboleta poderia causar um tufão em um local muito distante.

Na verdade, essa maneira popular de descrever certos acontecimentos não é assim tão ingênua. Muitos são os fenômenos que poderiam, cientificamente, merecer essa alcunha. Um exemplo disso foi o tornado que grandes proporções que ocorreu em fevereiro de 1998 nos Estados Unidos, em Orlando, Flórida (Kissimme e Tornado Outbreak), e que foi posteriormente associado com uma movimentação do ar em maior velocidade na região do Alaska.

Com o passar do tempo houve a constatação de que muitos são os fenômenos que apresentam essa característica de grandes efeitos a partir de pequenas, e as vezes remotas, 
causas. Eles ocorrem em muitas áreas distintas, como nos estudos de dinâmica populacional, mercado financeiro, movimento de placas tectônicas, funcionamento do cérebro e tantos outros.

Tal realidade instigou a investigação e conduziu a comunidade científica à uma tentativa de abordagem em conjunto desses fenômenos, surgindo em decorrência disto o estudo da teoria do caos ou, como posteriormente designado, o estudo dos sistemas complexos, que envolve muitas ciências em um esforço conjunto de compreensão.

Neste trabalho, será feita uma abordagem informal e de caráter bastante geral dos sistemas complexos. Para atingir esse objetivo é apresentada uma caracterização intuitiva, que pode ser aceita comumente, a partir desta serão realizados alguns raciocínios que o autor julga pertinentes e interessantes.

\section{SISTEMAS COMPLEXOS}

Um conceito que frequentemente aparece associado aos sistemas complexos é o de

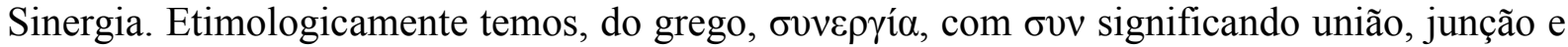

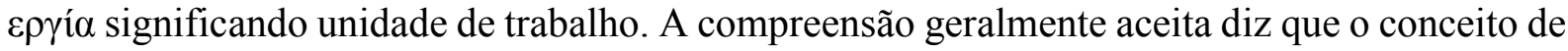
Sinergia nos dá a ideia de como: "o todo pode ser maior que a soma das partes", ou ainda, como "o resultado oriundo da combinação de dois ou mais elementos, é maior do que o resultado obtido somando-se os resultados dos mesmos separadamente". Essa é uma dentre as diversas características que são comuns aos fenômenos que nos interessam.

No caso de sistemas complexos as partes, às quais nos referimos acima, apresentam o que pode ser chamada de micro-propriedades. As partes próximas realizam micro-interações, produzindo um comportamento, que ao se propagar, tem características caóticas, uma vez que: apresentam macro-propriedades que não têm correlação com as micro-propriedades que estão em sua causa; resistem à modelagem e à previsibilidade longa no tempo.

A abordagem de tais sistemas mostra-se mais eficaz, quando apresenta o caráter multidisciplinar, assim é que matemática, física, química, biologia, economia, ciência de computação e outras, colaboram com o seu melhor, na tentativa de modelar esses fenômenos.

Algumas propriedades, que são gerais o bastante para serem passíveis de aceitação pela maioria dos que buscam compreender tais sistemas, são apresentadas a seguir: 
i) Sistemas complexos transitam entre a instabilidade e a estabilidade em curtíssimos intervalos de tempo, dificultando e/ou inviabilizando a previsibilidade de longo prazo;

ii) Os sistemas complexos são constituídos de um grande número de agentes que interagem, cada um em uma vizinhança próxima, produzindo incessantes modificações micro e macroscópicas;

iii) $\mathrm{Na}$ fronteira dessas micro-interações, surgem ações antagônicas que impedem, uma a outra, o desfecho que cada uma pressupõe;

iv) Os diversos agentes que participam das micro-interações do sistema, acumulam e dissipam, abruptamente, grande quantidade de energia;

v) As correlações entre as micro-interações se desenvolvem no tempo e na estrutura, produzindo uma auto-organização conectante;

vi) Macro-propriedades qualitativas podem emergir do sistema, as quais não possuem nenhuma correlação com as micro-propriedades apresentadas nas partes;

vii) Os equilíbrios momentâneos do sistema são muito tênues e quebrados por pequenas perturbações que sejam (NUSSENZVEIG, 1999).

As características descritas acima podem ser identificadas, de uma maneira muito intuitiva, por exemplo, no estudo do clima.

\section{O MÉTODO DE DESCARTES}

Em 1637 em seu Discours de la methode, René Descartes apresentou um "discurso sobre o método para bem conduzir a razão na busca da verdade dentro da ciência” (DESCARTES, 2009). Descartes apresenta, com a certeza que julga alcançar devido a relevância dada à autoridade da razão, um modelo quase matemático para conduzir o pensamento. Assim é que, em seu método, ele propõe quatro preceitos que podem ser apresentados (a partir de uma visão simplista) da seguinte maneira:

1) Não aceitar de pronto a informação como verdadeira, mas examiná-la com base na racionalidade, avaliando sua justificação;

2) Analisar a informação dividindo-a em tantas partes quanto possível e necessário, reconhecendo objetos mais simples que a compõem;

3) Promover a Síntese, ou elaboração progressiva de conclusões abrangentes e ordenadas, almejando os objetos mais complexos e elaborados;

4) Enumerar e recapitular as conclusões de modo a compor um todo coerente. 
Se observarmos com atenção, sob um certo ponto de vista, as formas mentais elementares na construção do pensamento humano, indução, dedução e enumeração, são contemplados no método proposto por Descartes.

\section{PARALELO}

Tendo em vista as considerações apresentadas, o leitor é convidado a nos acompanhar em uma argumentação, que busca justificar as dificuldades no estudo dos sistemas complexos, como um efeito da natureza dos fenômenos abordados por tais sistemas. Ao nosso ver tais fenômenos apresentam um caráter que resiste ao método de Descartes.

Observe inicialmente que a decomposição dos fenômenos de um sistema complexo em partes menores, como proposta em (2), não trará informações significativas sobre o todo, tendo em vista (vi).

Muito embora as correlações do sistema produzam uma auto-organização conectante, como visto em (v), não podemos esquecer que o sistema também transita da instabilidade para a estabilidade muito rapidamente, como visto em (i), e que os equilíbrios momentâneos são quebrados por pequenas perturbações, como visto em (vii). O que, ao nosso ver, impede ou dificulta, sobremaneira, a composição de um todo coerente, como prescrito em (4).

Decorre ainda, que o tempo gasto para realizar a síntese e a enumeração proposta em (3) e (4), por menor que seja (devido aos avanços computacionais), conduz à uma imagem, que é anacrônica, e não retrata mais o fenômeno, tendo em vista que o reestabelecimento constante do equilíbrio, muda muito rapidamente sua configuração, como visto em (i) e (ii).

Talvez, uma das mais notáveis incompatibilidade entre o método e a característica da complexidade está na execução da análise e da síntese que, ao nosso ver, será sempre frustrada em decorrência de (iii).

O paralelo apresentado não tem o objetivo de construir um ponto de vista paralisante, objetiva apenas estimular a discussão, confrontando um objeto moderno de estudo com uma abordagem clássica de raciocínio sobre a realidade. Ademais, as diversas disciplinas têm, efetivamente, apresentado muitos instrumentos buscando capturar as características dos sistemas complexos que lhe são peculiares.

Abaixo apresentaremos, de uma forma bastante intuitiva, algumas abordagens da matemática para a noção de complexidade. 


\section{MATEMÁTICA NA COMPLEXIDADE}

Ao longo da história, a matemática sempre foi eficaz em oferecer ao homem estruturas abstratas que facilitaram a árdua tarefa de compreensão e organização do, cada vez mais complexo, ambiente científico. Os modelos para os problemas de contagem e de medida, por exemplo, foram decisivos na organização do mundo moderno, e o que dizer do cálculo diferencial e integral, ferramenta fundamental e indispensável ao estudo das diversas ciências e no desenvolvimento da tecnologia.

$\mathrm{Na}$ abordagem matemática que temos interesse neste artigo, entenderemos sistema como um processo no qual: uma vez inseridos os dados iniciais, a partir de certas manipulações dos mesmos, são obtidos os dados de saída. No caso em que, tanto os dados iniciais, quanto os de saída, sejam funções contínuas no tempo, o sistema será chamado de contínuo. Em geral, tais sistemas são constituídos por várias equações diferenciais (isto é, equações que envolvem uma função incógnita e suas derivadas), estas devem ser resolvidas simultaneamente. A resolução do sistema é o processo que fornece os dados de saída, e estes são constituídos pelas funções incógnitas encontradas.

Existe ainda, a situação na qual, tanto os dados iniciais, quanto os de saída são discretos no tempo (isto é, são sequências de números), neste caso temos os chamados sistemas discretos, que são constituídos pelas equações de diferenças finitas. Para uma abordagem formal dos conceitos matemáticos que aqui são apresentados intuitivamente, veja (HILBORN, 1994) e/ou (MONTEIRO, 2002) e/ou (DEVANEY, 2003).

Nos sistemas contínuos o sistema de equações diferenciais modelam um fenômeno, isto é, as soluções do sistema, que são funções contínuas, descrevem relações entre os agentes e os resultados produzidos a partir da interação desses mesmos agentes.

Faremos distinção entre sistemas:

i) Variantes ou invariantes no tempo, na medida em que os coeficientes das equações diferenciais que compõem tal sistema sejam, ou não, constantes;

ii) Lineares ou não-lineares, conforme as equações diferenciais que compõem o sistema apresentem, ou não, produtos entre as funções incógnitas;

Nos sistemas lineares vale o princípio da superposição, na medida em que respostas podem ser obtidas separadamente e depois combinadas, eles modelam fenômenos nos quais os efeitos são proporcionais às causas. 
Já os sistemas não-lineares modelam fenômenos em que os efeitos não guardam proporcionalidade com as causas. Nestes não é válido o princípio de superposição e embora atendam de forma mais precisa a modelação de sistemas complexos eles são, em geral, muito mais difíceis de serem resolvidos do que os sistemas lineares.

No universo dos sistemas não-lineares, temos a classe daqueles conhecidos como sistemas dinâmicos com comportamento caótico. Nestes últimos podemos traduzir a ideia de sensitividade com relação às condições iniciais, ou de desproporcionalidade entre causa e efeito (caos), dizendo que, dois pontos muitíssimo próximos, em um curto intervalo de tempo, podem ficar completamente separados, ou ainda que, as trajetórias destes pontos, que inicialmente estão muito próximas, divergem exponencialmente no tempo.

Para avaliar a presença de caos em um sistema dinâmico temos, por exemplo, o conceito do expoente de Lyapunov, que busca quantificar a dependência, em relação aos dados iniciais, de um sistema não-linear. Tal expoente tem uma forma muito técnica de ser calculado e retrata quando o sistema expande (caso seja positivo) ou contrai (caso seja negativo) medindo dessa forma como órbitas próximas se afastam.

O matemático russo Aleksandr Mikhailovich Lyapunov (1857-1918) foi um precursor do estudo dos sistemas dinâmicos e da teoria da estabilidade, propondo vários conceitos e obtendo muitos resultados que se tornaram clássicos nesse estudo (HEDRIH, 2007).

De uma maneira geral a abordagem matemática dos sistemas complexos é bastante técnica, exigindo uma linguagem muito elaborada, e um volume muito grande de conhecimentos prévios no campo de diversas subáreas da matemática.

O que segue, a título de ilustração, é o sistema de equações diferenciais ordinárias nãolineares, de primeira ordem, proposto por Lorenz em 1963. Ele foi proposto como um modelo simplificado de conversão atmosférica. Assim, temos:

$$
\begin{gathered}
\dot{x}=-10 x+10 y \\
\{\dot{y}=-x z+28 x-y \\
\dot{z}=\quad x y-8 / 3 z
\end{gathered}
$$

Tal sistema, originado a partir da situação bem concreta do estudo do clima, apresenta um comportamento atípico, no sentido de que o conjunto limite para toda solução não constante é altamente não trivial e conhecido como "atrator estranho". 
A palavra atrator designa uma região do espaço de configurações que fica invariante com o fluir do tempo e que atrai quase todas as configurações (órbitas) próximas. Já o atrator para o qual as trajetórias que à ele convergem, dependem sensitivamente do ponto inicial, dáse o nome de atrator estranho, sendo o sistema de Lorenz o mais notório a apresentar tal característica. Podemos pensar em uma pista de corrida bastante larga, com um formato bastante peculiar, onde os carros transitam em diferentes velocidades descrevendo diferentes caminhos, sem dela sair. Além disso, todos os carros na vizinhança da pista para ela afluem.

Resolver um sistema de equações, como o acima, é encontrar três funções incógnitas: $x(t), y(t), z(t)$,na variável independentet (tempo), de tal forma que, substituindo tais funções no sistema dado, as igualdades se verifiquem para todos os valores de $t \geq 0$. Os símbolos $\dot{x}, \dot{y}$ e $\dot{z}$ indicam as derivadas de primeira ordem das funções $x(t), y(t), z(t)$, e medirão a taxa de variação da posição, por unidade de tempo, de uma partícula que se desloca regida por tais funções.

\section{UM POUCO DE GEOMETRIA}

Com as notações mencionadas acima, consideraremos a função vetorial $P(t)=(x(t)$, $y(t), z(t))$, na qual as funções coordenadas, $x(t), y(t), z(t)$, são as soluções do sistema de Lorenz. A cada instante de tempo $t$ o vetor $P(t)$ indica um estado da atmosfera, este vetor é identificado então com um ponto no espaço tridimensional cartesiano. Tal ponto se desloca na medida em que o tempo passa e os estados atmosféricos mudam. A linha percorrida no espaço com o passar do tempo descreve a imagem da função vetorial $P(t)$, chamaremos tal linha de trajetória (ou órbita) percorrida pelo ponto (ou partícula), a partir de uma posição inicialP(0).

A princípio, partículas que iniciam suas trajetórias de pontos distintos descrevem órbitas distintas. Porém, em nosso caso, tais órbitas convergem para uma mesma região do espaço (atrator), embora dentro de uma mesma região, as trajetórias são muito díspares e dizemos que elas divergem (atrator estranho). Assim, no caso das soluções para o sistema de Lorenz, temos um atrator estranho, cuja configuração será retratada nos gráficos tridimensionais que seguem. Devido ao fato de o atrator guardar uma incrível semelhança com uma borboleta de asas abertas, surgiu o termo "efeito borboleta". 
Na Figura 1, temos a ilustração da trajetória (órbita) de uma partícula. O planoStenta produzir uma perspectiva que retrate mais fielmente a órbita tridimensional desta partícula. Os pontos $C_{1}$ e $C_{2}$, são produzidos quando o sistema de Lorenz tem $\dot{x}(t)=\dot{y}(t)=\dot{z}(t)=0$.

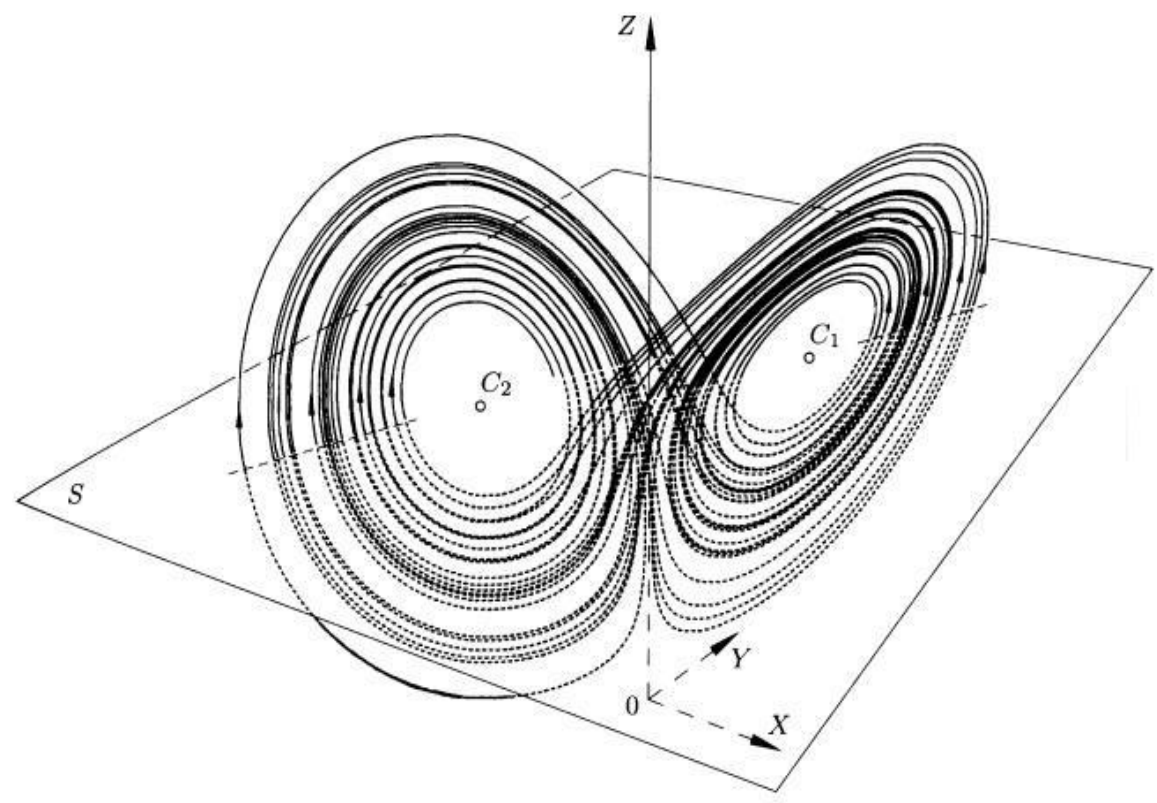

Figura 1 - Trajetória (órbita) de uma partícula em um sistema cartesiano de coordenadas. Fonte: The Impact of Chaos on Science and Society, 1997.

$\mathrm{Na}$ figura 2, temos a mesma ideia retratada em um outro sistema de coordenadas, o objetivo é dar mais clareza na observação da trajetória.

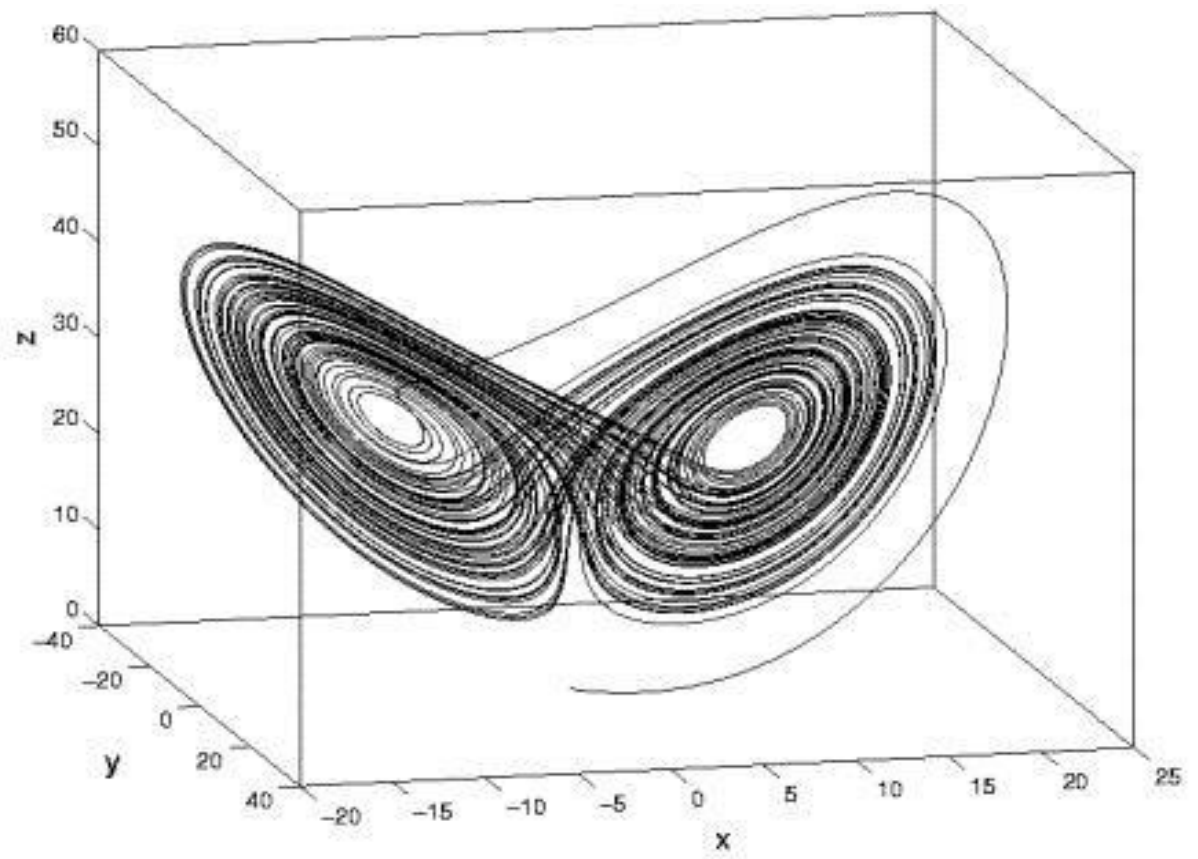


Figura 2 - Trajetória de uma partícula em um sistema cartesiano, distinto, de coordenadas. Fonte: Estocasticidade, 2013.

Na Figura 3, é apresentada uma caracterização mais artística, que retrata o "efeito borboleta" e pode ser útil para aqueles que não estão muito acostumados com representações geométricas.

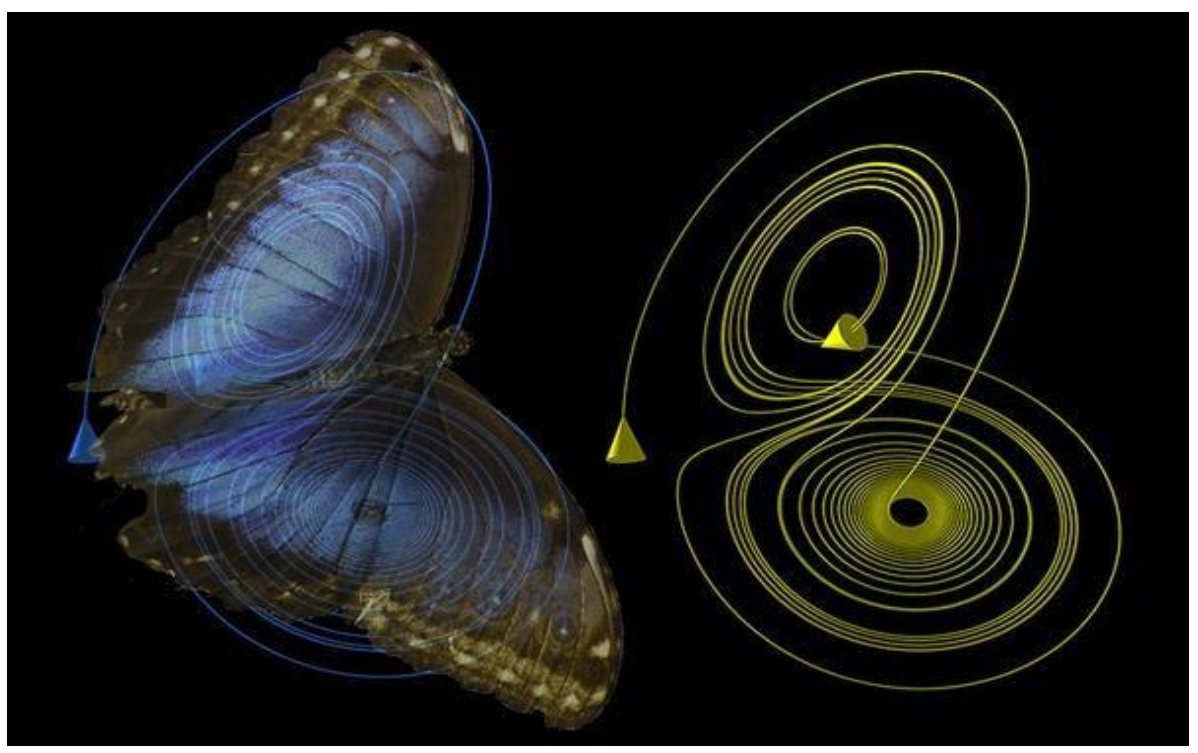

Figura 3 - Efeito borboleta.

Fonte: Hyperscience, 2011.

$\mathrm{Na}$ medida em que duas partículas iniciam suas trajetórias, a partir de dois pontos distintos, muitíssimos próximos, uma vez que estão sobre a influência do mesmo atrator, percorrem regiões do espaço estabelecidas pelo mesmo. Porém, com o passar do tempo, suas trajetórias começam a se diferenciar dentro dessa região, e o distanciamento observado é bastante significativo.

A interpretação matemática para o comportamento descrito acima, caracteriza a desproporcionalidade entre as causas (que é medida pela mudança muito pequena na posição inicial das partículas) e os efeitos (que é medido pelo distanciamento drástico nas trajetórias das mesmas).

Para representar geometricamente essa situação, exibimos as figuras 4, 5 e 6 . Nestas, são apresentadas duas partículas que começam suas trajetórias a partir de pontos muito próximos um do outro. Para ser mais preciso, a simulação é feita com as partículas partindo de pontos que diferem apenas em suas coordenadas $x$, e a diferença é de apenas 0,00001. A 
trajetória de cada partícula será indicada por uma linha e, para distingui-las, uma terá a cor amarela a outra terá a cor azul.

Na Figura 4, praticamente só vemos a linha amarela, isso decorre do fato de que no intervalo de tempo considerado, que é pequeno, as partículas ainda não caminharam o suficiente para evidenciar seu distanciamento. Suas trajetórias, sobre o atrator, são ainda muito próximas, ao ponto de as linhas amarela e azul estarem aparentemente sobrepostas (na verdade não estão sobrepostas, o efeito decorre de nossa limitação física em representa-las) além disso, a própria região do atrator não está completamente determinada e clara.

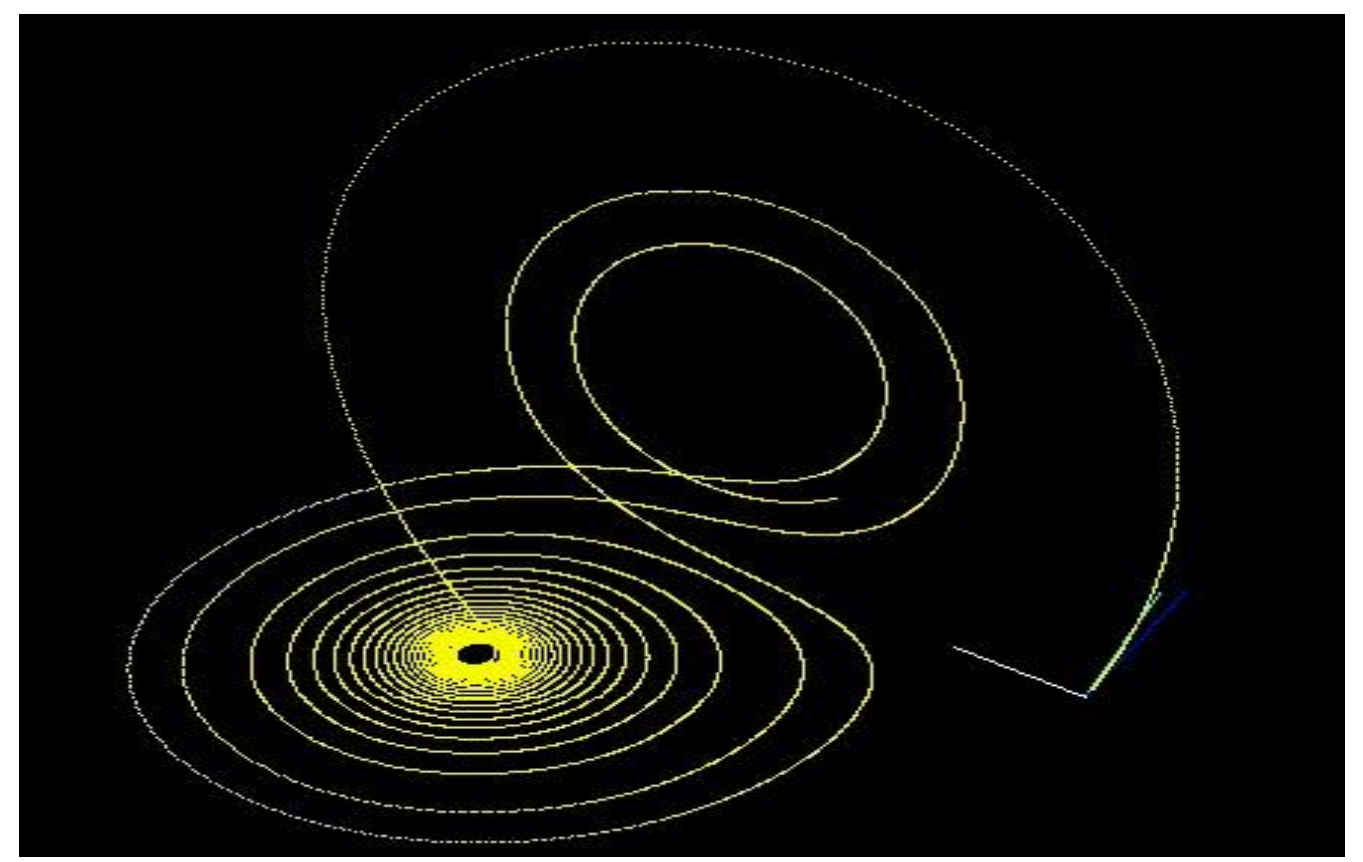

Figura 4 - Trajetórias iniciais são praticamente indistinguíveis sobre o atrator. Fonte: Wikipédia, 2013.

Na Figura 5, o intervalo de tempo decorrido a partir do início $(t=0)$, é maior do que aquele considerado na Figura 4.As trajetórias caminham na região do atrator porém, já apresentam um distanciamento mais significativo, de modo que é possível identificar as linhas de cores diferentes. 


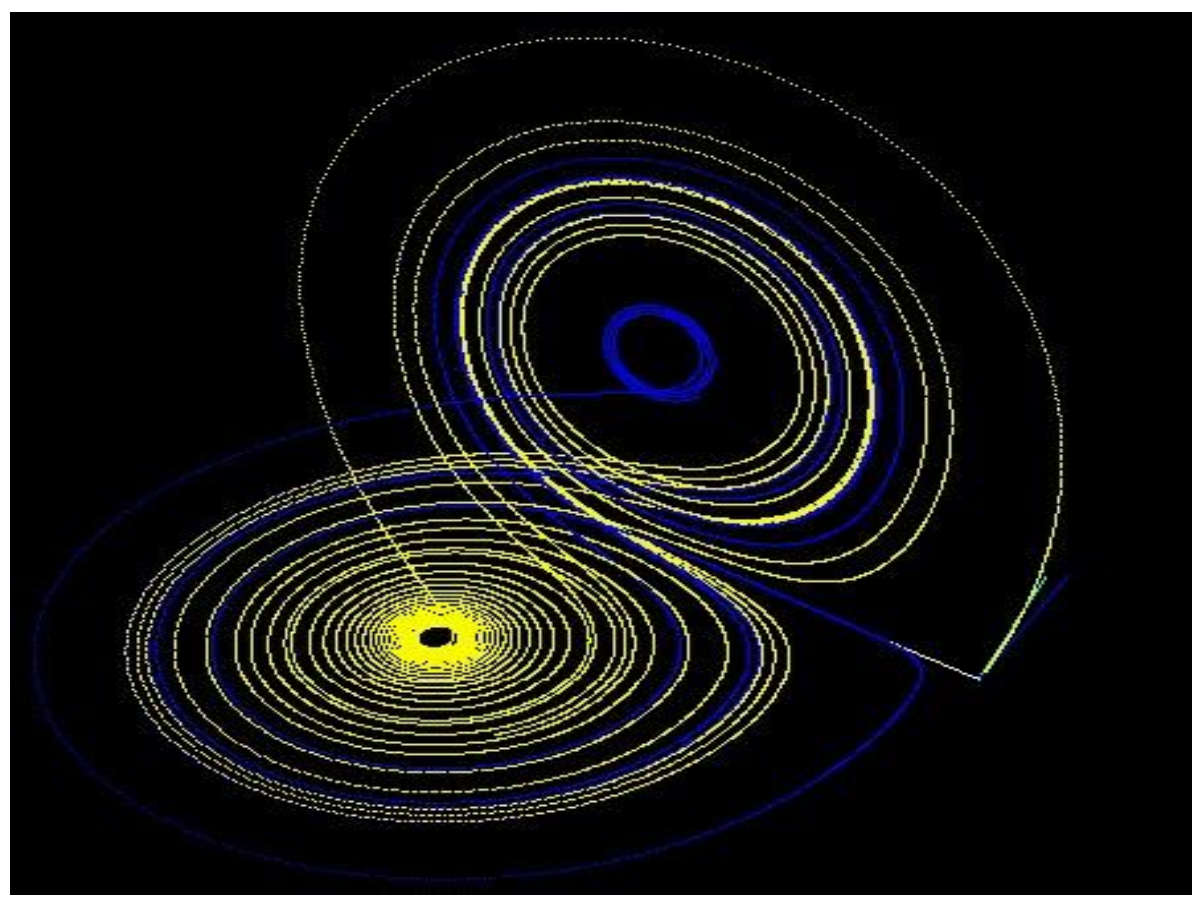

Figura 5 - As trajetórias dão indícios de distanciamento com o passar do tempo.

Fonte: Wikipédia, 2013.

Finalmente, na Figura 6, que corresponde à um intervalo de tempo maior do que aquele considerado nas figuras anteriores, podemos identificar claramente o distanciamento (divergência) entre as duas trajetórias, por meio do distanciamento notório das diferentes cores. A região do atrator já está, também, bastante pronunciada.

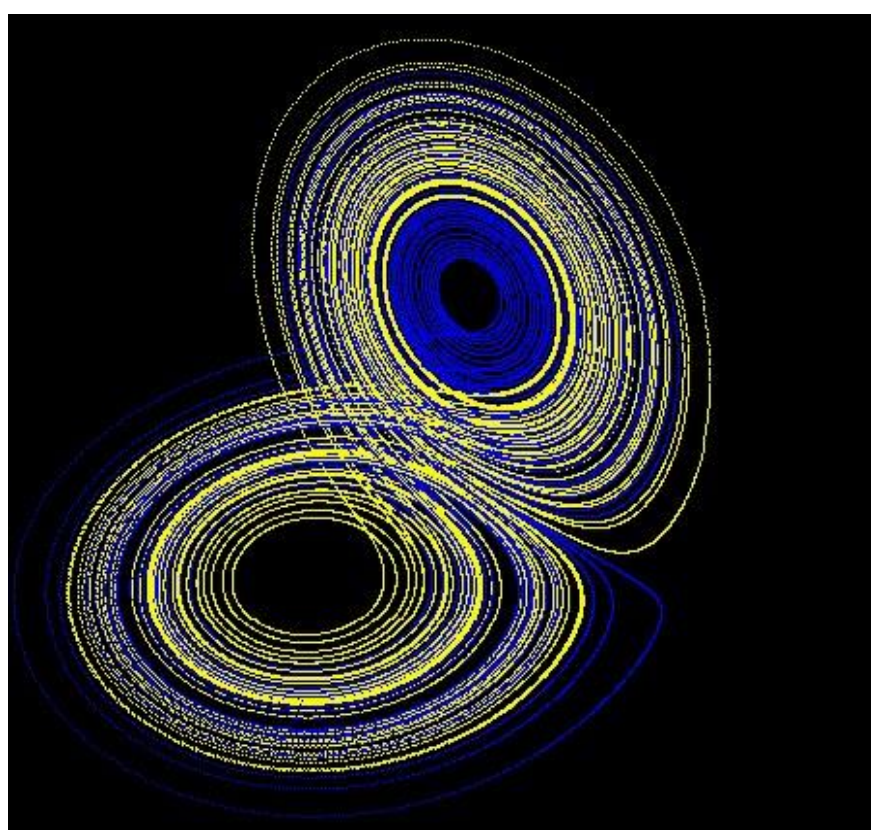


Figura 6 - As trajetórias tornam-se notoriamente distintas configurando o atrator.

Fonte: Wikipédia, 2013.

\section{COMSIDERAÇÕES FINAIS}

Os estudos de sistemas complexos têm se mostrado bastante profícuos, muitas pessoas, em diversas áreas, têm procurado entender e descrever os fenômenos que tais sistemas abrangem, e estes não são poucos. Os avanços constantes, principalmente na tecnologia computacional, tanto em software como em hardware, tem oferecido ferramentas cada vez mais poderosas para enfrentar os desafios propostos.

As tentativas de abordagem multidisciplinar são cada vez mais constantes, e mais promissoras. A apresentação feita neste pequeno trabalho é tremendamente simplificada, nosso objetivo é despertar a curiosidade dos leitores para esse incrível e vastíssimo campo de estudos. Nas referências bibliográficas, além de livros e artigos, é apresentado um link que pode ser de interesse para aqueles que desejem mais informações sobre o tema. As figuras apresentadas neste trabalho estão espalhadas pela rede de internet e são de livre acesso.

\section{REFERÊNCIAS}

CHAOS. CHAOS VII: STRANGE Lyapunov. Scientific Technical Review, vol. LVII, ATTRACTORS. The Butterfly Effect. Disponível $\quad$ N $^{\circ} 2,2007$.

em: <http://www.chaos-math.org/en/chaos-viistrange-attractors>. Acesso em: 03 de mai. 2016.

DESCARTES, René. Discurso do Método. São Paulo: WMF Martins Fontes, 2009.

DEVANEY, Robert Luke. Chaotic Dynamical System. Boulder: Westview Press, 2003.

ESTOCASTICIDADE. $O$ atrator de Lorenz. 2013. Disponível em:

<https://estocasticidade.wordpress.com/2013/04/

29/o-atrator-de-lorenz/>. Acesso em: 02 de mai. 2016.

GREBOGI, Celso; YORKE, James. The impact of chaos on science and society. Tokio: United Nations University Press, 1997.

HEDRIH, Katica Stevanovic. Nonlinear Dynamics and Aleksandr Mikhailovich
HILBORN, Robert C. Chaos and nonlinear dynamics: $\mathrm{Na}$ introduction for scientists and engineers.New York: Oxford University Press, 1994.

HYPESCIENCE. O efeito borboleta realmente existe?. 2011. Disponível em: $<$ http://hypescience.com/uma-borboleta-que-

bate-as-asas-aqui-pode-mesmo-causar-umtornadodo-outro-lado-do-mundo/>. Acesso em: 02 de mai. 2016.

LORENZ, Edward Norton. Deterministic Nonperiodic Flow. Journal of the Atmospheric Sciences: vol 20, 130-141, 1963.

MONTEIRO, Luiz Henrique Alves. Sistemas Dinâmicos. $2^{\circ}$ Edição. São Paulo: Livraria da Física, 2002. 
NUSSENZVEIG, Herch Moysés. Complexidade e and human genomes. Nature, 2012, p. 486, 527Caos. Rio de Janeiro: Editora Ufrj/Copea, 1999. 531.

PRÜFER, Kay; MUNCH, Kasper et al. The bonobo genome compared with the chimpanzee 
SOARES, Marcelo Reicher. Matemática e Complexidade. Complexitas - Rev. Fil. Tem., Belém, v. 1, n. 1, p. 63-77, jan./jun. 2016. Disponível em:< http://www.periodicos.ufpa.br/index.php/complexitas/article/view/3413>. Acesso em: 04 jul. 2016. 